\title{
Where will Non-Vitamin K Oral Anticoagulants Stand beyond being Standard of Care in Anticoagulation Therapy?
}

\author{
Oktay Ergene \\ Department of Cardiology, Faculty of Medicine, Dokuz Eylul University, Izmir, Turkey \\ ORCID: \\ Oktay Ergene: https://orcid.org/0000-0003-1775-4063
}

\section{Abstract}

Objective: Atrial fibrillation (AF) is the most common arrhythmia that increases risk of stroke by 4-5 fold. AF prevalence is approximately $1 \%-3 \%$ in the general population and increases with age. Until 2010, the standard of care (SoC) for prophylaxis of ischemic stroke was Vitamin $\mathrm{K}$ antagonists. Phase III randomized controlled trials (RCTs) of non-Vitamin K oral anticoagulants (NOACs) showed that NOACs have comparable or lower risk of stroke, systemic embolism, major bleeding, and death with warfarin in populations with nonvalvular AF (NVAF). Since then, results of these pivotal RCTs were confirmed by postmarketing studies and real-world data. In the last 8 years, they have been replacing warfarin as the SoC not only for preventing stroke in NVAF patients but also for patients with deep vein thrombosis, pulmonary embolism, and those who undergo hip or knee surgery. In recent years, there are emerging data on new clinical areas such as coronary and peripheral artery disease. In this article, it is attempted to review what has changed in the last 8-10 years in the management and prevention of stroke associated with NVAF and other thromboembolic situations and to foresee whether NOACs will be SoC and stand beyond being SoC in anticoagulation therapy. Methods: IMS data were obtained from IQVIA with a permission letter on request of Dr. Ergene. IQVIA grants permission to use the statements for the specified purpose (NOACs share in the total anticoagulation market and role of NOACs as the SoC in the near future) of peer-review publication by Dr. Ergene. Conclusion: NOACs are breakthrough in stroke prevention, and they will prevail eventually. It will take a few years; anticoagulation market will grow in favor of NOACs, and most probably, NOACs will reach over 50\% standard unit market share. It is even more exciting to hear about new therapeutic areas and indications for these agents.

Keywords: Atrial fibrillation, oral anticoagulants, randomized controlled trials

\section{INTRODUCTION}

Atrial fibrillation (AF) is the most frequently encountered cardiac arrhythmia with a prevalence of $1 \%-3 \%$ in the general population, reaching $15 \%$ in elderly population. Therewithal, it also poses a 4-5-fold increased risk of ischemic stroke, which is increased for elderly patients and a 2-fold increased risk of all-cause mortality. ${ }^{[1-4]}$ On the other hand, AF is a disease with a high economic burden for both patients and healthcare providers. $^{[5]}$ Because of these catastrophic consequences of AF, anticoagulation therapy is indispensable and the standard of care (SoC) for these patients for many years with Vitamin $\mathrm{K}$ antagonists (VKA) although some major drawbacks such as bleeding. ${ }^{[6]}$ Non-Vitamin $\mathrm{K}$ antagonists (NOACs) such as dabigatran, rivaroxaban, apixaban, and edoxaban have come a

Submission: 21-Feb-19 Revision: 16-Apr-19 Accepted: 20-May-19

\begin{tabular}{|l|l|}
\hline \multicolumn{2}{c|}{ Access this article online } \\
\hline Quick Response Code: & Website: \\
& \\
&
\end{tabular}

long way to become standard therapy. Since 2010, all 4 NOACs have proven their efficacy and safety profile for the prevention of stroke in patients with nonvalvular AF (NVAF). The first evidences in terms of efficacy and safety were obtained with their phase III dose-adjusted, warfarin-controlled, randomized-controlled trials (RCTs). These pivotal trials demonstrated that similar or improved efficacy of NOACs compared with warfarin, in addition to reduced rates of intracranial and life-threatening bleeding. ${ }^{[7-10]}$ A meta-analysis published in 2014 showed that all NOACs had a favorable risk-benefit profile with a significant reduction in stroke,

Address for correspondence: Prof. Oktay Ergene, Department of Cardiology, Faculty of Medicine, Dokuz Eylul University, Mithatpasa Cad. No 1606 Inciralti Yerleskesi, 35340 Balcova, Izmir, Turkey. E-mail: oktayergene@yahoo.com.tr

This is an open access journal, and articles are distributed under the terms of the Creative Commons Attribution-NonCommercial-ShareAlike 4.0 License, which allows others to remix, tweak, and build upon the work non-commercially, as long as appropriate credit is given and the new creations are licensed under the identical terms.

For reprints contact: reprints@medknow.com

How to cite this article: Ergene O. Where will non-Vitamin $\mathrm{K}$ oral anticoagulants stand beyond being standard of care in anticoagulation therapy?. Int J Cardiovasc Acad 2019;5:75-9. 
intracranial hemorrhage, and all-cause mortality, and with similar major bleeding as for warfarin. ${ }^{[11]}$ In the last 5 years, various and numerous real-world data confirmed these phase III clinical trial outcomes, especially in terms of combined endpoint of intracranial hemorrhage or ischemic stroke. ${ }^{[12-14]}$

Recent trials which have been conducted in the last couple of years promise wider use of NOACs in new therapeutic areas. One of these new areas is about the use of NOACs in patients with NVAF receiving antiplatelet therapy after percutaneous coronary intervention (PCI). ${ }^{[15-17]}$ Another area is uninterrupted anticoagulation during AF ablation. NOACs became an alternative to VKAs in these procedures. ${ }^{[18,19]}$ In the pathogenesis of acute coronary syndromes (ACSs), plaque disruption and factor Xa play a central role in activation of the coagulation cascade. For this purpose, low-dose rivaroxaban added to dual antiplatelet therapy (DAPT) was tested whether it will improve cardiovascular $(\mathrm{CV})$ outcomes in patients with ACS. ${ }^{[20]}$ It revealed better CV outcomes in the cost of slightly increased risk of bleeding. It might be a new therapeutic option in high-risk ACS patients. In an another recently published trial, low-dose rivaroxaban was tested instead of aspirin with P2Y12 inhibitor in ACS patients. It revealed the safety of rivaroxaban in this setting. ${ }^{[21]}$ In patients with chronic ischemic heart disease, proved antithrombotic strategy is antiplatelet therapy mainly with aspirin. A multicenter trial was conducted whether rivaroxaban alone or in combination with aspirin is more effective than aspirin alone to prevent the recurrence of CV events in patients with stable atherosclerotic disease. ${ }^{[22]}$ This study results with a paradigm shift to anticoagulant therapy in these patient population. Another new therapeutic area is venous thromboembolic disease. In the initial phase of the treatment only rivaroxaban $15 \mathrm{mg}$ bid and apixaban $10 \mathrm{mg}$ bid strategies which approved by regulatory authorities are alternative to VKAs. ${ }^{[23-25]}$ All of the four NOACs approved for remainder of treatment phase. Furthermore, a recently published trial showed benefits of rivaroxaban in extended therapy in chronic phase of venous thromboembolism instead of aspirin. ${ }^{[26]}$

In summary, in the last 10 years, the development and widespread use of NOACs lead an abundant change and paradigm shift in many therapeutic and preventive areas of $\mathrm{CV}$ diseases. Hereafter, it seems that this conversion will expand in other therapeutic areas.

In this article, we tried to review what has changed in the last decade in the management and prevention of stroke associated with NVAF. We also reviewed the evidences which issued NOAC use in other thromboembolic and CV diseases to foresee whether NOACs will be SoC and stand beyond being $\mathrm{SoC}$ in anticoagulation therapy.

\section{Methods}

IMS data were obtained from IQVIA with a permission letter on request of Dr. Ergene. IQVIA grants permission to use the statements for the specified purpose (NOACs share in the total anticoagulant market and role of NOACs as the $\mathrm{SoC}$ in the near future) of peer-review publication by Dr. Ergene. The data are used in accordance with applicable laws and Turkish regulatory authority (Turkish Medicines and Medical Devices Agency).

\section{RESULTS}

IMS data of global anticoagulant market showed that trend for either the decrease in VKAs market share or the increase in NOACs market share is continuing in the period from 2014 to 2017 as VKAs decreased from $71.3 \%$ to $51.5 \%$; on the contrary, NOACs increased from $16 \%$ to $35.7 \%$ from 2014 to 2017 [Figure 1].

\section{Discussion}

The use of warfarin tends to decrease in the last years due to an increase in NOAC use for several reasons. Time in therapeutic range (TTR) adjustment for warfarin-treated patients is difficult and unpredictable because of its narrow therapeutic window, wide variability in anticoagulant effect, and food/ drug interactions. ${ }^{[27-31]}$ TTR data obtained from the real world are much lower than retrieved from randomized controlled trials. ${ }^{[32]}$ The clinical practice guidelines extend the criteria for antithrombotic use and currently recommend NOACs over warfarin. $^{[33]}$

$\mathrm{AF}$ is the most frequent reason for using oral anticoagulant, whereas ACSs (either ST- or non-ST-elevation myocardial infarction or unstable angina) are the leading indication for PCI with stent implantation. Among ACS patients undergoing PCI, approximately $5 \%-21 \%$ of patients have concomitant AF. ${ }^{[15]}$ DAPT plus OAC treatment (triple therapy) that has been used in these patients as a standard treatment has a higher incidence of major bleeding than single antiplatelet plus oral anticoagulant therapy which was shown in WOEST trial. ${ }^{[34]}$ Therefore, one of the trial arm was planned as P2Y12 plus rivaroxaban $15 \mathrm{mg}$ combination without aspirin therapy in phase III PIONEER AF-PCI trial. PIONEER AF-PCI is the first prospective

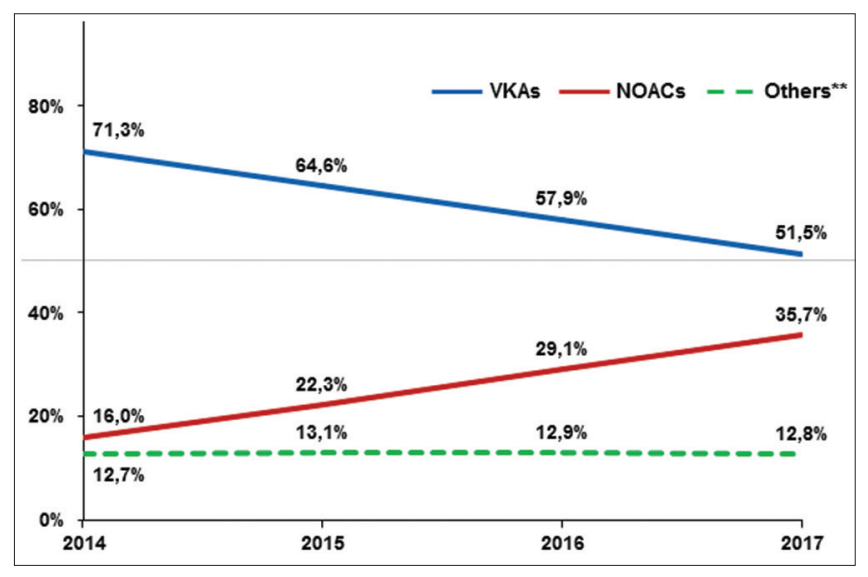

Figure 1: Global AC market volume shares in \% (based on DoT*). Source: IQVIA MIDAS, Database: Current All 2017. *DoT = days of therapy, calculated based on volume in SU (standard units). DoT = SU (1 tablet per day) except for dabigatran and apixaban: DoT = SU divided by 2 (two tablets per day) (Adopted with permission from IQVIA Database) 
study which evaluated two rivaroxaban dosing regimens. In addition to the above-mentioned dosing regimen, rivaroxaban $2.5 \mathrm{mg}$ twice daily (BID) plus DAPT compared with VKA in patients with NVAF receiving concomitant antiplatelet therapy after PCI, to assess the relative risks of bleeding complications. ${ }^{[15]}$ Rivaroxaban is the first NOAC (versus VKA) which demonstrated significantly improved safety in this patient population. The reduced dose of rivaroxaban $15 \mathrm{mg}$ OD plus single antiplatelet therapy could become a treatment option in this clinical scenario. ${ }^{[15]}$ Other NOACs also have interest in this therapeutic area. In the RE-DUAL PCI study which was recently announced, the safety of dabigatran 110 and $150 \mathrm{mg}$ were compared with warfarin. Both dosing regimens showed significantly lower rates of major bleeding. ${ }^{[16]}$

In patients with ACS, DAPT is used as standard therapy. Despite this treatment regimen, it is known that there is a residual $\mathrm{CV}$ risk. ${ }^{[20]}$ A residual $\mathrm{CV}$ risk may be due to the persistence of activation of the coagulation system and significant thrombin formation for several months after clinical stabilization. This may be explaining the rationale for the use of anticoagulant therapy to further reduce recurrent events. ${ }^{[20]}$ Although the benefits of adding warfarin to treatment have been shown in some studies during the last two decades, warfarin has not found a place in this therapeutic area due to the concern of increased bleeding. ${ }^{[28,29,31,32]}$ Recently, two different low doses of rivaroxaban in addition to DAPT were tested for $\mathrm{CV}$ outcomes and safety in ATLAS ACS 2-TIMI 51. ${ }^{[20]}$ Rivaroxaban showed a significant reduction in the primary efficacy endpoints of death from CV causes, myocardial infarction, or stroke in patients with a recent ACS and $2.5 \mathrm{mg}$ dose also showed a survival benefit. Regarding safety, there was a nonsignificant slight increase in bleeding with $5 \mathrm{mg}$ dose of rivaroxaban. Conversely, APPRAISE-2 trial which has evaluated apixaban, was prematurely terminated due to an excessive risk of intracranial hemorrhage and major bleeding with triple antithrombotic therapy without a benefit in the risk of recurrent ischemic events. ${ }^{[35]}$ Hereafter, the so-called "vascular dose" is proposed for the low dose of rivaroxaban in patients with ACS. ATLAS ACS-2 TIMI 51 findings demonstrate that increased thrombin activity may play a role in ACS and that NOACs such as rivaroxaban may be a useful option in this treatment regimen. ${ }^{[20]}$ On the other hand, aspirin which has shown benefit in terms of its antiplatelet effect inhibits only the thromboxane A2-dependent pathway of platelet. ${ }^{[36]}$ Since aspirin has a limited antiplatelet effect, a factor $\mathrm{Xa}$ inhibitor instead of aspirin was tested in GEMINI study. ${ }^{[21]}$ In this study, it was aimed to assess the safety of using a low dose of the oral anticoagulant rivaroxaban instead of aspirin in patients treated with a P2Y12 inhibitor (either clopidogrel or ticagrelor) in patients with ACS. The similar risk of TIMI non-CABG clinically significant bleeding with rivaroxaban versus aspirin was observed. In summary, low-dose rivaroxaban had similar risk of clinically significant bleeding as aspirin in patients with ACSs. ${ }^{[21]}$

At the beginning of the last decade, it was determined that DAPT was more effective yet with more bleeding events compared to single acetylsalicylic acid therapy in CURE study. ${ }^{[36]}$ On the other hand, the combination of warfarin and aspirin has shown improved efficacy profile with an increased bleeding rate. Subsequently, ATLAS ACS-2 TIMI 51 study showed improved CV outcomes with an acceptable safety profile with rivaroxaban $2.5 \mathrm{mg}$ bid plus DAPT. The results of this study inspired COMPASS trial; it was conducted whether rivaroxaban alone or in combination with aspirin is more effective than aspirin alone to prevent the recurrence of CV events in patients with stable atherosclerotic disease. One of the most important features of this study was that it was the most comprehensive phase III study conducted in almost 27000 patients who have coronary artery and/ or peripheral artery disease, and the study was terminated early due to the overwhelming efficacy since it has met its primary endpoint significantly ahead of time. According to the results of this study, although the rate of major bleeding was higher with the combination of rivaroxaban $2.5 \mathrm{mg}$ bid plus ASA than with aspirin alone as expected, a composite of $\mathrm{CV}$ death, stroke, or myocardial infarction was found lower. As a result, the net clinical benefit outcome was better. ${ }^{[22]}$

Recent retrospective cohort study of Medicare beneficiaries sought to determine patterns of apixaban use and its associated outcomes in dialysis-dependent patients with end-stage renal disease (ESRD) and AF. The study showed that among patients with ESRD and AF on dialysis, apixaban use may be associated with a lower risk of major bleeding compared with warfarin, with a standard $5 \mathrm{mg}$ twice a day dose also associated with reductions in thromboembolic and mortality risk. ${ }^{[37]}$ Recent ACC/AHA focused update paper issued apixaban and warfarin treatment in patients with ESRD with IIb recommendation level. However, its important to recognize that this study has only hypothesis generating not confirming fashion. ${ }^{[38]}$

VKA has been the standard therapy for patients with a mechanical prosthetic valve, or bioprosthesis with AF. The Dabigatran versus Warfarin in Patients with Mechanical Heart Valves (RE-ALIGN) trial comparing dabigatran etexilate to warfarin was the only randomized controlled study in patients with mechanical valve prosthesis, but it was terminated prematurely because of an excess of thromboembolic and bleeding events among patients in the dabigatran group. ${ }^{[39]}$ To date, use of NOACs is contraindicated for AF patients with mechanical prosthetic valves. The hypothesis of eligibility of use of factor Xa inhibitors in mechanical heart valves was discussed in a recent published paper. ${ }^{[40]}$ The authors emphasize that 1 single trial with a single NOAC does not represent sufficient evidence for dismissing a therapeutic strategy, anticoagulation with NOACs and further experimentation should be conducted in this important area.

In the light of this overwhelming data related to NOACs that we tried to summarize, there are 3 basic questions that must be answered.

Can the NOACs be used in all indications for which warfarin is indicated? Starting from the release of the new agents in 
the market, how has the dynamics changed for the global anticoagulant market? What is the future of NOACs in new indications and new therapeutic areas?

The answer of the first question is almost yes. According to clinical practice guidelines, other than severe mitral stenosis and prosthetic valves, NOACs can be used nearly in all indications that VKAs are indicated. In patients with NVAF when oral anticoagulation is indicated, clinical practice guidelines recommend NOACs in preference to a VKA.

The answer of the second question is more complicated and more related to the subject of this article. The answer is not straight forward due to confounding factors such as cost effectiveness and VKAs familiarity of healthcare providers. To what extent are the physicians aware of the benefits of NOACs over VKAs and how much do they adapt to these advantages. On the other hand, healthcare providers have some hesitation in their practice of anticoagulation with VKAs, mostly because of the concerns about bleeding.

The United States (US) health statistics showed that from 2001 to 2011, the relative rate of stroke death decreased by $35 \%{ }^{[4]}$ At that time, this decline was achieved by risk factor management such as controls of hypertension, diabetes, high cholesterol, and smoking cessation. However, the big step was AF management mostly by anticoagulation with VKAs. As NOACs were approved by European and US regulatory agencies in 2008, a contribution of NOAC use to this decline in stroke rate should not be negligible. Although some meta-analysis showed a 19\% reduction in stroke and systemic embolism and significantly reduced all-cause mortality with NOACs compared to VKAs, there are no real-world data concerning this issue. ${ }^{[11]}$ Regarding to IMS, data of global anticoagulant market warfarin have declined from $87.5 \%$ to $72 \%$ through 2008-2014. In the same period, NOACs have reached $15.5 \%$ market share [Figure 2]. IMS data also show that same trend for either the decrease in VKAs market share or the increase in NOACs market share is continuing in the period from 2014 to 2017 as VKAs decreased from 71.3\% to 51.5\%; on the contrary, NOACs increased from $16 \%$ to $35.7 \%$ from 2014 to 2017. According to 2018 IQVIA Database, 50 million patients have been prescribed rivaroxaban since marketing launch. ${ }^{[42]}$ These data reveal that in the near future, NOACs will be the $\mathrm{SoC}$ in anticoagulation therapy.

The third question, what is the future of NOACs in new indications and new therapeutic areas? It is hard to answer this question also, at least now. There are substantial data about factor Xa inhibitor usage in acute and chronic ischemic atherosclerotic heart and peripheral arterial disease albeit only with rivaroxaban. Nevertheless, it is quite early to decide whether in these new therapeutic areas, we should use factor Xa inhibitor, namely rivaroxaban. However, the 2018 European Heart Rhythm Association practical guide recommend low-dose ( $2.5 \mathrm{mg}$ bid) rivaroxaban in patients with ACS and for secondary prevention of atherothrombotic events in stable CAD in addition to aspirin. ${ }^{[33]}$ Consequently, U.S. Food and Drug Administration,

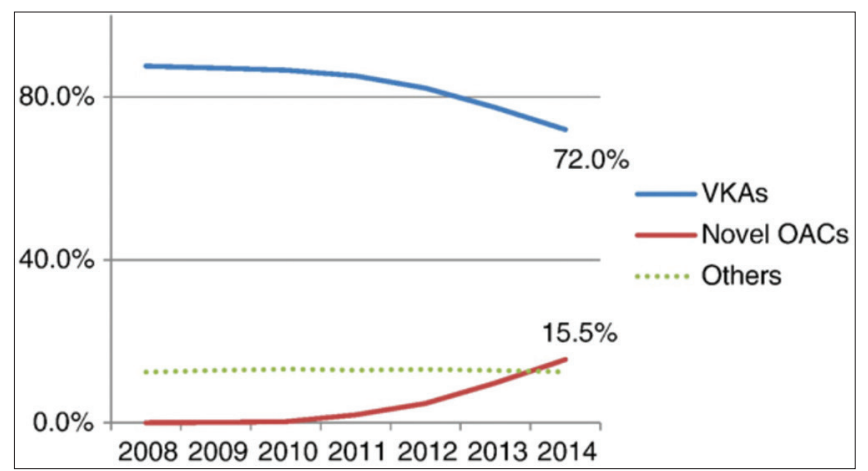

Figure 2: Global AC market volume shares in \% (based on DoT*). Source: IMS MIDAS, Database: Current All 2014. ${ }^{\star}$ DoT = days of therapy, calculated based on volume in SU (standard Units) (Adopted with permission from IQVIA Database)

European Medicine Agency and Turkish Medicines and Medical Devices Agency (TITCK) have approved rivaroxaban to reduce the risk of major $\mathrm{CV}$ events, such as $\mathrm{CV}$ death, myocardial infarction and stroke, in people with chronic coronary, or peripheral artery disease. In the near future, medical society will continue discussing the controversial term "vascular dose" of rivaroxaban. We do not know whether there are "vascular doses" of other NOACs. Somehow, it is clear that there is a need for more randomized trials in this new therapeutic areas and new indications for anticoagulant drugs.

\section{Conclusion}

As the time pass by, numerous articles regarding the real-world data about NOACs appear on the medical literature. In general, the efficacy and safety of NOACs are confirmed by these real-world data. These drugs are breakthrough in stroke prevention, and they will prevail eventually. It will take a few years; anticoagulation market will grow in favor of NOACs, and most probably, NOACs will reach over $50 \%$ standard unit market share. It is even more exciting to hear about new therapeutic areas and indications for these agents.

\section{Acknowledgment}

The author would like to thank Bayer Corporation for thoughtful supports.

\section{Financial support and sponsorship}

Nil.

\section{Conflicts of interest}

The author has made a speech in the field of NOACs for Bayer, Daiichi Sankyo, Pfizer, and Boehringer Ingelheim. The author declares full independence from this funding as to the content of this article.

\section{RefEREnCes}

1. Wolf PA, Abbott RD, Kannel WB. Atrial fibrillation as an independent risk factor for stroke: The Framingham study. Stroke 1991;22:983-8.

2. Kirchhof P, Auricchio A, Bax J, Crijns H, Camm J, Diener HC, et al. Outcome parameters for trials in atrial fibrillation: Executive summary. Eur Heart J 2007;28:2803-17. 
3. Benjamin EJ, Wolf PA, D'Agostino RB, Silbershatz H, Kannel WB, Levy D. Impact of atrial fibrillation on the risk of death: The Framingham heart study. Circulation 1998;98:946-52.

4. Andersson T, Magnuson A, Bryngelsson IL, Frøbert O, Henriksson KM, Edvardsson N, et al. All-cause mortality in 272,186 patients hospitalized with incident atrial fibrillation 1995-2008: A Swedish nationwide long-term case-control study. Eur Heart J 2013;34:1061-7.

5. Santos JV, Pereira J, Pinto R, Castro PM, Azevedo E, Freitas A. Atrial fibrillation as an ischemic stroke clinical and economic burden modifier: A 15-year nationwide study. Value Health 2017;20:1083-91.

6. Hart RG, Pearce LA, Aguilar MI. Meta-analysis: Antithrombotic therapy to prevent stroke in patients who have nonvalvular atrial fibrillation. Ann Intern Med 2007;146:857-67.

7. Connolly SJ, Ezekowitz MD, Yusuf S, Eikelboom J, Oldgren J, Parekh A, et al. Dabigatran versus warfarin in patients with atrial fibrillation. N Engl J Med 2009;361:1139-51.

8. Patel MR, Mahaffey KW, Garg J, Pan G, Singer DE, Hacke W, et al. Rivaroxaban versus warfarin in nonvalvular atrial fibrillation. N Engl J Med 2011;365:883-91.

9. Granger CB, Alexander JH, McMurray JJ, Lopes RD, Hylek EM, Hanna $\mathrm{M}$, et al. Apixaban versus warfarin in patients with atrial fibrillation. N Engl J Med 2011;365:981-92.

10. Giugliano RP, Ruff CT, Braunwald E, Murphy SA, Wiviott SD, Halperin JL, et al. Edoxaban versus warfarin in patients with atrial fibrillation. N Engl J Med 2013;369:2093-104.

11. Ruff CT, Giugliano RP, Braunwald E, Hoffman EB, Deenadayalu N, Ezekowitz MD, et al. Comparison of the efficacy and safety of new oral anticoagulants with warfarin in patients with atrial fibrillation: A meta-analysis of randomised trials. Lancet 2014;383:955-62.

12. Coleman CI, Antz M, Bowrin K, Evers T, Simard EP, Bonnemeier H, et al. Real-world evidence of stroke prevention in patients with nonvalvular atrial fibrillation in the United States: The REVISIT-US study. Curr Med Res Opin 2016;32:2047-53.

13. Coleman CI, Antz M, Ehlken B, Evers T. REal-LIfe evidence of stroke prevention in patients with atrial fibrillation - The RELIEF study. Int J Cardiol 2016;203:882-4.

14. Coleman CI, Antz M. Real-world evidence with apixaban for stroke prevention in patients with nonvalvular atrial fibrillation in Germany: A retrospective study (REASSESS). Intern Emerg Med 2017;12:419-22.

15. Gibson CM, Mehran R, Bode C, Halperin J, Verheugt F, Wildgoose P, et al. An open-label, randomized, controlled, multicenter study exploring two treatment strategies of rivaroxaban and a dose-adjusted oral Vitamin $\mathrm{K}$ antagonist treatment strategy in subjects with atrial fibrillation who undergo percutaneous coronary intervention (PIONEER AF-PCI). Am Heart J 2015;169:472-8.e5.

16. Cannon CP, Bhatt DL, Oldgren J, Lip GYH, Ellis SG, Kimura T, et al. Dual antithrombotic therapy with dabigatran after PCI in atrial fibrillation. N Engl J Med 2017;377:1513-24.

17. Kirchhof P, Benussi S, Kotecha D, Ahlsson A, Atar D, Casadei B, et al. 2016 ESC guidelines for the management of atrial fibrillation developed in collaboration with EACTS. Eur Heart J 2016;37:2893-962.

18. Cappato R, Marchlinski FE, Hohnloser SH, Naccarelli GV, Xiang J, Wilber DJ, et al. Uninterrupted rivaroxaban vs. uninterrupted Vitamin $\mathrm{K}$ antagonists for catheter ablation in non-valvular atrial fibrillation. Eur Heart J 2015;36:1805-11.

19. Stepanyan G, Badhwar N, Lee RJ, Marcus GM, Lee BK, Tseng ZH, et al. Safety of new oral anticoagulants for patients undergoing atrial fibrillation ablation. J Interv Card Electrophysiol 2014;40:33-8.

20. Mega JL, Braunwald E, Wiviott SD, Bassand JP, Bhatt DL, Bode C, et al. Rivaroxaban in patients with a recent acute coronary syndrome. N Engl J Med 2012;366:9-19.

21. Ohman EM, Roe MT, Steg PG, James SK, Povsic TJ, White J, et al. Clinically significant bleeding with low-dose rivaroxaban versus aspirin, in addition to $\mathrm{P} 2 \mathrm{Y} 12$ inhibition, in acute coronary syndromes (GEMINI-ACS-1): A double-blind, multicentre, randomised trial. Lancet 2017;389:1799-808.

22. Eikelboom JW, Connolly SJ, Bosch J, Dagenais GR, Hart RG,
Shestakovska $\mathrm{O}$, et al. Rivaroxaban with or without aspirin in stable cardiovascular disease. N Engl J Med 2017;377:1319-30.

23. EINSTEIN Investigators, Bauersachs R, Berkowitz SD, Brenner B, Buller HR, Decousus H. Oral rivaroxaban for symptomatic venous thromboembolism. N Engl J Med 2010;363:2499-510.

24. Schulman S, Kearon C, Kakkar AK, Mismetti P, Schellong S, Eriksson $\mathrm{H}$, et al. Dabigatran versus warfarin in the treatment of acute venous thromboembolism. N Engl J Med 2009;361:2342-52.

25. Agnelli G, Buller HR, Cohen A, Curto M, Gallus AS, Johnson M, et al. Oral apixaban for the treatment of acute venous thromboembolism. N Engl J Med 2013;369:799-808.

26. Weitz JI, Lensing AW, Prins MH, Bauersachs R, Beyer-Westendorf J, Bounameaux $\mathrm{H}$, et al. Rivaroxaban or aspirin for extended treatment of venous thromboembolism. N Engl J Med 2017;376:1211-22.

27. Holbrook AM, Pereira JA, Labiris R, McDonald H, Douketis JD, Crowther M, et al. Systematic overview of warfarin and its drug and food interactions. Arch Intern Med 2005;165:1095-106.

28. Verhovsek M, Motlagh B, Crowther MA, Kennedy C, Dolovich L, Campbell $\mathrm{G}$, et al. Quality of anticoagulation and use of warfarin-interacting medications in long-term care: A chart review. BMC Geriatr 2008;8:13.

29. Ansell J, Hirsh J, Poller L, Bussey H, Jacobson A, Hylek E. The pharmacology and management of the Vitamin $\mathrm{K}$ antagonists: The seventh ACCP conference on antithrombotic and thrombolytic therapy. Chest 2004;126:204S-233S

30. Franco V, Polanczyk CA, Clausell N, Rohde LE. Role of dietary Vitamin $\mathrm{K}$ intake in chronic oral anticoagulation: Prospective evidence from observational and randomized protocols. Am J Med 2004;116:651-6.

31. Blann AD, Fitzmaurice DA, Lip GY. Anticoagulation in hospitals and general practice. BMJ 2003;326:153-6.

32. Almutairi AR, Zhou L, Gellad WF, Lee JK, Slack MK, Martin JR, et al. Effectiveness and safety of non-Vitamin $\mathrm{K}$ antagonist oral anticoagulants for atrial fibrillation and venous thromboembolism: A systematic review and meta-analyses. Clin Ther 2017;39:1456-78.e36

33. Steffel J, Verhamme P, Potpara TS, Albaladejo P, Antz M, Desteghe L, et al. The 2018 European Heart Rhythm Association practical guide on the use of non-Vitamin $\mathrm{K}$ antagonist oral anticoagulants in patients with atrial fibrillation. Eur Heart J 2018;39:1330-93.

34. Dewilde WJ, Oirbans T, Verheugt FW, Kelder JC, De Smet BJ, Herrman JP, et al. Use of clopidogrel with or without aspirin in patients taking oral anticoagulant therapy and undergoing percutaneous coronary intervention: An open-label, randomised, controlled trial. Lancet 2013;381:1107-15.

35. Sherwood MW, Lopes RD, Sun JL, Liaw D, Harrington RA, Wallentin L, et al. Apixaban following acute coronary syndromes in patients with prior stroke: Insights from the APPRAISE-2 trial. Am Heart J 2018;197:1-8.

36. Yusuf S, Zhao F, Mehta SR, Chrolavicius S, Tognoni G, Fox KK, et al. Effects of clopidogrel in addition to aspirin in patients with acute coronary syndromes without ST-segment elevation. N Engl J Med 2001;345:494-502

37. Siontis KC, Zhang X, Eckard A, Bhave N, Schaubel DE, He K, et al. Outcomes associated with apixaban use in patients with end-stage kidney disease and atrial fibrillation in the United States. Circulation 2018;138:1519-29.

38. January CT, Wann LS, Calkins H, Chen LY, Cigarroa JE, Cleveland JC Jr., et al. 2019 AHA/ACC/HRS focused update of the 2014 AHA/ACC/ HRS guideline for the management of patients with atrial fibrillation. Circulation 2019;140:e125-e151.

39. Eikelboom JW, Connolly SJ, Brueckmann M, Granger CB, Kappetein AP, Mack MJ, et al. Dabigatran versus warfarin in patients with mechanical heart valves. N Engl J Med 2013;369:1206-14.

40. Aimo A, Giugliano RP, De Caterina R. Non-Vitamin K antagonist oral anticoagulants for mechanical heart valves. Circulation 2018;138:1356-65.

41. Mozaffarian D, Benjamin EJ, Go AS, Arnett DK, Blaha MJ, Cushman M, et al. Heart disease and stroke statistics-2015 update: A report from the American Heart Association. Circulation 2015;131:e29-322.

42. IQVIA MIDAS, Database Quarterly Sales Q4 2018. 